\title{
THE QUESTION OF «VESTIGIAL NEOLITHIC» FOREST-STEPPE DON
}

(C) 2019

\author{
Stavitsky Vladimir Vyacheslavovich, doctor of historical sciences, \\ professor of General History and Social Science Department \\ Penza State University (Penza, Russian Federation)
}

Abstract. The concept of «vestigial Neolithic» was presented by A.T. Sinyuk in his thesis and hasn't undergone any significant changes. It was based on statistical and stratigraphic observations of Universitetskaya 3 settlement. Here three Neolithic stages and the fourth stage «vestigial Neolithic» were identified. Its beginning was connected with the appearance of the population of the lower Don Eneolithic culture on the Middle Don, which contacted with the tribes of fish culture. The findings were based on the assumption that the economy of the Rybnoserskaya culture was appropriating, while the economy of the Nizhnedonskaya culture was producing. The possibility of their coexistence was explained by the rich ecological resources of the forest-steppe Don, as well as the focus on the extraction of different food resources. New materials have not confirmed the Neolithic nature of the Nizhnedonskaya culture. The topography of the settlements indicates that both local and alien tribes occupied the same ecological niche. The beginning of the Eneolithic period on the Middle Don should be associated with the Middle Eastern culture, the population of which displaced or assimilated the aborigines. There wasn't any period of coexistence of Eneolithic and Neolithic (survivable) cultures either on the Middle Don, or in the forest-steppe Volga region.

Keywords: vestigial Neolithic; archaeological era; stratigraphy; Eneolithic; Srednedonskaya culture; Nizhnedonskaya culture; Srednestogovskaya culture; forest-steppe; Middle Don; pit-comb ceramics; conducting economy; inter-ethnic contacts; funeral ceremony; Rybnoserskaya culture; ecological niche.

УДК 902

DOI 10.24411/2309-4370-2019-12221

\section{СРЕДНЕДОНСКАЯ НЕОЛИТИЧЕСКАЯ КУЛЬТУРА: ПРОБЛЕМЫ ВЫДЕЛЕНИЯ, ХРОНОЛОГИИ И ПЕРИОДИЗАЦИИ}

(C) 2019

Сурков Алексей Владимирович, кандидат исторических наук, археолог Центр охранных археологических исследований (г. Воронеж, Российская Федерация)

Аннотация. В статье рассматриваются основные итоги изучения среднедонской неолитической культуры. Отмечается вклад А.Т. Синюка в ее выделение и дальнейшее изучение. Прослежена эволюция его взглядов на содержание раннего этапа культуры по мере изучения неолитических стоянок на Дону. Так, первая периодизация, сделанная в 1971 г. по итогам изучения стоянки Университетская III, затем была скорректирована, особенно после раскопок стоянки Монастырская 1. Хронология культуры по современным представлениям укладывается в IV-V тыс. до н.э. Происхождение среднедонской культуры является дискуссионным. Новые абсолютные датировки позволяют рассматривать ранний этап в рамках первой половины VI - третьей четверти VI тыс. до н.э. и связывать его с первыми памятниками с накольчатой керамикой и пластинчатым каменным инвентарем, отмечается взаимодействие среднедонского населения с карамышевским на раннем этапе. Развитой этап - последняя четверть VI - первая четверть V тыс. до н.э., распространение накольчатогребенчатой посуды, орнамент полностью заполняет внешнюю поверхность сосудов. Поздний этап - вторая четверть V - конец V тыс. до н.э., формирование синкретических типов - черкасского, накольчато-ямочного. Пережиточный этап - начало IV тыс. до н.э., финал среднедонских традиций, слабовыраженный в рыбноозерском типе керамики.

Ключевые слова: неолит; археологическая культура; периодизация; хронология; лесостепной Дон; р. Воронеж; Побитюжье; стоянка Университетская III; стоянка Монастырская 1; стоянка Ступино; стоянка Доброе 9; стоянка Васильевский кордон 7; керамика; орнаментация; накол; карамышевская культура; среднедонская культура.

Прошло уже полстолетия с момента выявления и первых раскопок среднедонских неолитических стоянок А.Т. Синюком. В этом году мы отмечаем 80летний юбилей исследователя, в связи с чем хотелось бы вновь обратиться к его научному наследию, к тому огромному потенциалу, который он раскрыл, изучая донские стоянки, заложив прочный фундамент дальнейших научных разработок.

\section{История изучения}

Неолитическая эпоха занимала важнейшее место в исследованиях Арсена Тиграновича, им была создана целостная картина развития материальной культуры населения этой эпохи в лесостепном Подонье $[1$, с. 167 , рис. 46]. Важной вехой в этом пути

стало выделение среднедонской культуры, самобытность которой была обоснована с анализом практически всех известных к тому времени памятников накольчатого и накольчато-гребенчатого неолита сопредельных территорий [2, с. 16].

Основой для выделения среднедонской культуры стали масштабные раскопки стоянок в пойме р. Воронежа при подготовке к затоплению поймы при строительстве Воронежского водохранилища в нижнем течении реки.

О большом количестве древних поселений в черте г. Воронежа было известно еще в довоенное время, Н.В. Валукинским была составлена карта памятников [3, с. 292, рис. 1]. К сожалению, эта коллекция 
Сурков А.В.

Среднедонская неолитическая культура: проблемы выделения.

07.00.00 - исторические науки и археология

была утрачена в годы войны, в связи с чем работы по изучению памятников в зоне затопления пришлось начинать практически с нуля. В 1967-1968 гг. А.Д. Пряхиным и А.Т. Синюком были проведены масштабные разведочные изыскания [4], а затем в 1968-1970 гг. - раскопки десяти наиболее значимых памятников.

Особое место среди исследованных памятников занимала стоянка Университетская III. Это был первый памятник, представивший развитие местного неолита-энеолита при относительно сохранившейся стратиграфии и выраженном культурном слое, раскопанный широкой площадью - $1576 \mathrm{M}^{2}$ [5, с. 26]. Именно материалы данной стоянки легли в основу кандидатского диссертационного исследования А.Т. Синюка, где им была посвящена отдельная глава [2, c. 7-13]. Специфика накольчатой керамики при выраженном пластинчатом характере каменного инвентаря позволила автору раскопок говорить о самостоятельном культурном статусе местных ранненеолитических древностей.

В 1970-е - начале 80-х гг. А.Т. Синюком были продолжены раскопки неолитических памятников на Среднем Дону, что нашло отражение в его докторской диссертации [6]. При этом содержание и периодизация среднедонской культуры были лишь немного уточнены.

В 1990-х гг. изучение памятников среднедонской культуры было продолжено его учениками. С.Н. Гапочка провел раскопки стоянки Щучье II в Побитюжье [7], а затем стоянок Затон I [8] и Дрониха, автором данной статьи велись раскопки в Похоперье [9] и на Верхнем Дону [10-12].

На Верхнем Дону также велось активное изучение неолитических памятников Р.В. Смольяниновым [13], что позволило внести корректировки в общую картину развития донского раннего неолита.

В последние десятилетия благодаря поддержке А.А. Выборнова была получена серия радиоуглеродных дат, позволившая определить хронологические рамки культур неолита и энеолита лесостепного Дона [14, с. 252-257].

Полученная на сегодняшний день источниковая база по неолиту лесостепного Подонья позволяет предпринять попытку анализа некоторых ключевых моментов касательно изучения среднедонской неолитической культуры.

\section{Хронология}

Время сложения среднедонской культуры, исходя из полученных абсолютных дат, определяется первой четвертью VI тыс. до н.э. [15, с. 367]. Наиболее ранними памятниками являются Черкасские стоянки и Монастырская I; полученная по фрагменту с накольчатой орнаментацией со стоянки Щучье II дата, уходящая в VII тыс. до н.э., вероятнее всего, некорректна, но, судя по типологии и условиям залегания, данный памятник также является ранним. Именно Побитюжье можно считать ядром культуры на раннем этапе.

К середине VI тыс. до н.э. среднедонские комплексы появляются в Верхнем Подонье, а даты, полученные по развитой среднедонской керамике, относятся к последней четверти этого тысячелетия [16, с. 59].

Среднедонские керамические традиции сохранялись, несмотря на проникновение в донскую лесо- степь нижнедонской энеолитической культуры в последней четверти VI тыс. до н.э., затем носителей культур с ямочно-гребенчатой орнаментацией керамики в начале $\mathrm{V}$ тыс. до н.э. и среднестоговской культуры в середине V тыс. до н.э. Такое длительное бытование является очень яркой чертой среднедонской культуры и сильно отличает ее от схожих культур сопредельных территорий. Можно констатировать доживание среднедонских традиций вплоть до первой четверти IV тысячелетия до н.э. На это указывают материалы многих памятников, например стоянки Ямное, где развалы среднедонских сосудов залегали на одном уровне со среднестоговскими, а формы накольчатых сосудов несут в себе черты долговской и среднестоговской культур [17].

\section{Генезис}

Самым слабым местом в изучении среднедонской культуры является проблема ее появления. Эта тема уже затрагивалась нами в одной из последних публикаций [18], в связи с чем еще раз отмечу, что мы пока не находим достоверно сопоставимых комплексов, которые могли бы лечь в основу сложения культуры.

Остается только искать различные «центры неолитизации», культура которых напрямую проникла на территорию Среднего Дона (в качестве одного из таких центров чаще всего упоминают Западный Прикаспий и Приаралье). Вариант опосредованной передачи отдельных навыков изготовления посуды пока не имеет доказательств.

Раннее появление среднедонской керамики справедливо ставится под сомнение, ведь на сопредельных территориях в неолитической посуде прослежена тенденция развития от неорнаментированных и слабоорнаментированных сосудов к орнаментированным по всей поверхности. На Верхнем Дону выделяется ранненеолитическая карамышевская культура, развитие которой происходит по указанному сценарию. Но существующие даты не позволяют нам рассматривать эту культуру как основу сложения среднедонской.

\section{Периодизация. Векторы развития}

В ходе изучения неолитических памятников Подонья А.Т. Синюк применил стандартную трехчленную периодизацию как всего донского неолита, так и среднедонской культуры, выделив ранний, развитой и поздний (пережиточный) этапы [19, с. 54].

В ходе исследований последних лет удалось обособить ранние материалы памятников в бассейне р. Воронеж (карамышевская культура), выделить ранненеолитические комплексы в Похоперье (Плаутино 1, 2. 4) и в низовьях р. Битюг (Черкасская 5).

Вероятнее всего, по р. Воронеж происходит основное распространение среднедонских керамических традиций, но наблюдаются различия в каменном инвентаре - пластинчатость зафиксирована только на Университетской III, тогда как севернее каменных орудий становится немного (по отношению к количеству керамики) и используется в основном отщеповая технология производства заготовок.

Интересно проследить развитие взглядов А.Т. Синюка на содержание раннего этапа среднедонской культуры, особенно в контексте выделения карамышевских древностей. Так, в своем кандидатском исследовании, основанном преимущественно на материалах стоянки Университетская III, к наиболее ран- 
ней керамике им отнесены прямостенные накольчатые горшки с растительной примесью [2, с. 16]. Второй же этап местного неолита выделялся А.Т. Синюком по появлению в тесте песка и редкому использованию гребенчатого штампа.

При публикации материалов стоянки Университетская III в 1978 г., по-видимому, с оглядкой на результаты работ на других неолитических памятниках, А.Т. Синюком было пересмотрено выделение групп керамики. Так, в первую группу были включены сосуды с преобладанием накольчатой орнаментации, редким использованием гребенчатого штампа и еще более редким прочерченным орнаментом [5]. По составу теста в этой группе преобладают с примесью песка, реже используется растительность и шамот. То есть хронологический приоритет керамики с «растительностью» был поставлен автором под сомнение.

В монографии 1986 г. позиция исследователя еще несколько меняется. Теперь гребенчатая керамика на стоянке Университетская III в силу своей малочисленности и вовсе не выделяется в отдельную группу, поскольку «чаще оттиски мелкогребенчатого штампа лишь дополняют орнамент из наколов» [1, с. 129].

Такая эволюция взглядов Арсена Тиграновича объясняется получением новых материалов по среднедонскому неолиту, где общие тенденции изменения неолитической керамики не совпадали с материалами Университетской III. Сейчас мы можем анализировать керамику Университетской III, учитывая выделенную карамышевскую культуру, что позволяет снять большинство противоречий. Для этого памятника под растительной примесью А.Т. Синюком понималось незапесоченное комковатое тесто, а современный анализ состава этой керамики, проведенный И.Н. Васильевой, позволяет соотнести ее с карамышевской культурой.

В коллекции Университетской III, хранящейся в фондах Воронежского областного краеведческого музея, достаточно керамики первого этапа карамышевской культуры (рис. 1). Она выделяется визуально по характеру заглаживания внешней поверхности до лощения, пористому комковатому тесту, орнаментации различными наколами и прочерками, форма сосудов прямостенная. Здесь есть керамика и аналогичная второму этапу карамышевской культуры (периодизация основана на исследовании стоянки Ступино, расположенной в 35 км севернее Университетских стоянок). Керамику второго этапа отличает появление песка в тесте, заглаживание обеих поверхностей сосудов регулярными мелкими расчесами, в орнаментации помимо различных наколов часто используется гребенка, сосуды имеют выраженный переход от тулова к дну (рис. 2).

Таким образом, материалы Университетской III отражают контакт населения карамышевской и среднедонской культур, при этом происходит обмен определенными приемами в изготовлении и декорировании посуды. Так, на среднедонских памятниках спорадически встречается гребенчатая орнаментация сосудов, а в керамике карамышевской культуре происходит заимствование основных среднедонских элементов в технологии производства керамики. Взаимодействие с среднедонским населением привело к появлению на карамышевской керамике глубоких наколов треугольной формы, запесоченного теста, регулярных мелких расчесов на поверхностях.
Ярким памятником, отражающим на Верхнем Дону определенный переход в керамике от ранней карамышевской к ее поздней форме, возникшей под влиянием среднедонской культуры, является стоянка Доброе 9 [20]. Отнесение этого памятника к карамышевским подтверждает и облик каменного инвентаря с выраженным отщеповым характером.

Возникает вопрос, а что же понимать под собственно среднедонской культурой.

Наиболее полно отражают ее содержание на раннем этапе материалы стоянки Монастырская I. Именно результаты раскопок этого памятника легли в основу выделения мезолита на Среднем Дону А.Т. Синюком и во многом повлияли на общую концепцию периодизации и содержания раннего этапа среднедонской культуры. При этом соотнесение каменного инвентаря стоянки с мезолитическим временем проведено только за счет планиграфического размещения материала в раскопе, а стратиграфического предшествования камня не было зафиксировано. Исследователем было отмечено генетическое родство населения, оставившего позднемезолитические и ранненеолитические материалы памятника [21, с. 265]. Здесь автором раскопок прослежен слабонасыщенный неолитический слой, характеризующийся в первую очередь накольчатой керамикой (ее около $90 \%$ ), при этом более половины наколов имеют треугольную форму, а скобковидные и спаренные наколы выполнены тем же инструментом. Форма сосудов цилиндрическая или коническая, остродонная, верх скруглен или приострен. Обязательным признаком является горизонтальный ряд ямок под венчиком [1, с. 61].

В нижних слоях Черкасской стоянки также доминирует накольчатый орнамент, причем он в основном треугольный, реже скобковидный [1, с. 85]. Каменный инвентарь нижних (неолитических) пластов памятника малоинформативный.

Аналогичные наблюдения были сделаны и на других неолитических памятниках (рис. 3).

Ранненеолитический камень характеризовался А.Т. Синюком как пластинчатый, вкладышевый при сохранении микролитоидного облика, что позволило связать эти материалы с Приаральем и СевероВосточным Прикаспием [1, с. 74-75].

Вопрос дальнейшего распространения гребенчатой орнаментации на среднедонской керамике не столь однозначен, поскольку в последней четверти VI тыс. до н.э. в лесостепном Подонье появляются носители нижнедонской культуры. Не затрагивая полемику отнесений этой культуры к неолиту или энеолиту, а также достоверность ранних дат этой культуры для донской лесостепи, отметим, что в конце IV тыс. до н.э. на рассматриваемой территории начинают появляться южные традиции, отличающиеся в первую очередь по керамике широким использованием короткозубой гребенки в декорировании сосудов, воротничковому оформлению венчиков, непропорционально маленьким плоским донцам. Повидимому, первые проникновения новых культурных традиций не повлекли каких-либо изменений в местной материальной культуре, и только в первой половине V тыс. до н.э. происходят определенные изменения, при этом общая картина неолитических древностей региона усложняется. 

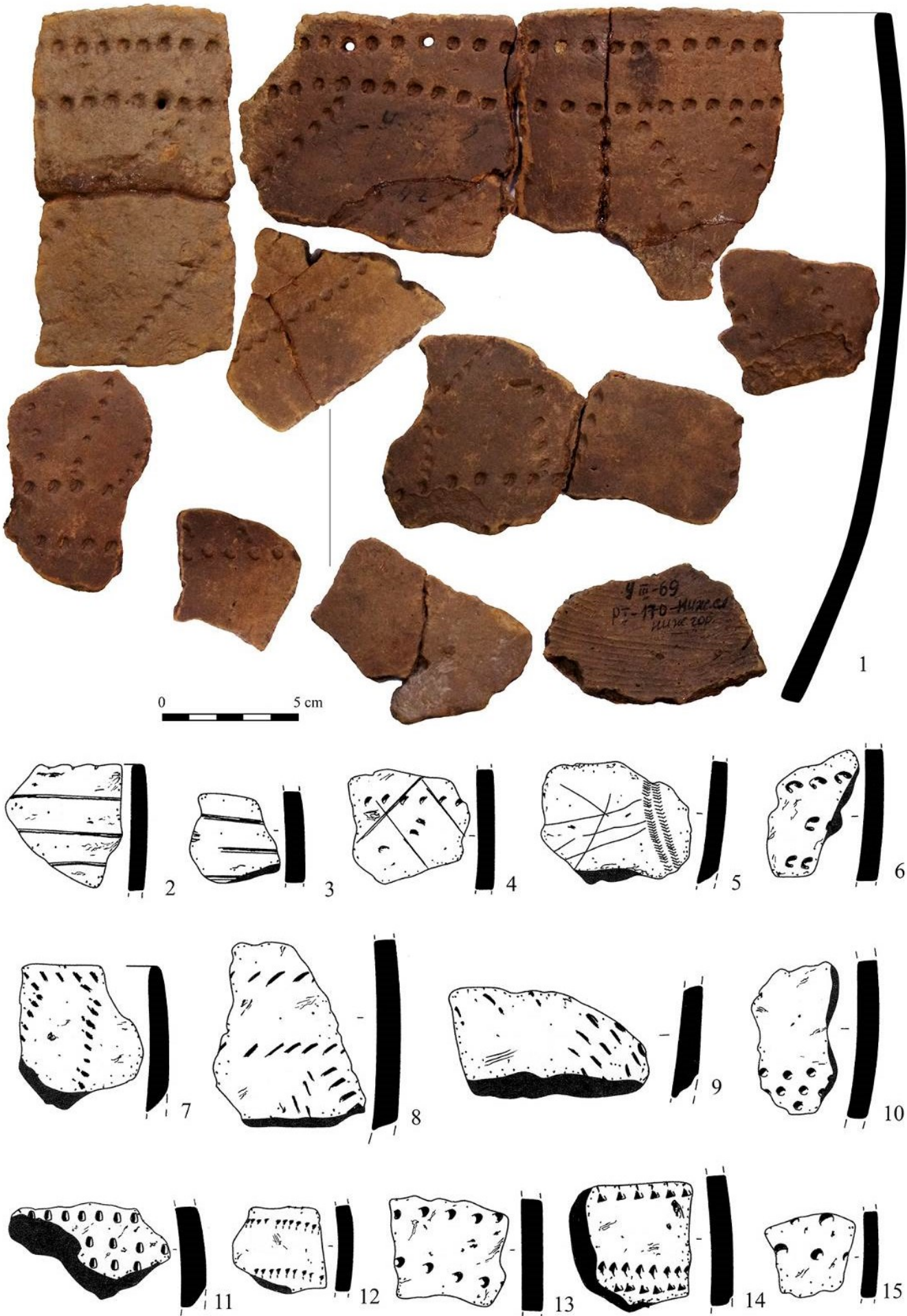

Рисунок 1 - Керамика первого этапа карамышевской культуры: 1-15- стоянка Университетская III

Именно с этим временем стоит связывать начало нового этапа в развитии среднедонской культуры, что справедливо отмечено А.М. Скоробогатовым $[22$, c. 20]. Главным отличием посуды этого этапа является сплошное густое декорирование поверхностей сосудов наколами, выстроенными в зоны из треугольных и наклонных композиций, разделенных горизонтально более глубокими вдавлениями.

Под влиянием нижнедонских керамических традиций формируется синкретический черкасский тип керамики, отражающий в равной мере влияние как пришлой, так и местной среднедонской культуры. Пока вопрос датирования этого типа недостаточно проработан - есть только пара дат, указывающих на вторую четверть V тыс. до н.э. [14, с. 246; 15, с. 367].
Подтверждает влияние нижнедонской культуры на среднедонскую анализ гончарных традиций, проведенный И.Н. Васильевой [23, с. 367]. Так, вся нижнедонская керамика с Университетской III и Ивницы была изготовлена из илов, тогда как типично среднедонская изготавливалась преимущественно из илистых глин и лишь среди относительно поздних среднедонских материалов со стоянок Университетская III, Черкасская I, Липецкое озеро также отмечено использование илов. Илы использовались и при производстве керамики черкасского типа. В этом контексте интересно отметить, что илы как основа, исходное пластичное сырье, отмечены и для керамики дронихинской культуры. 

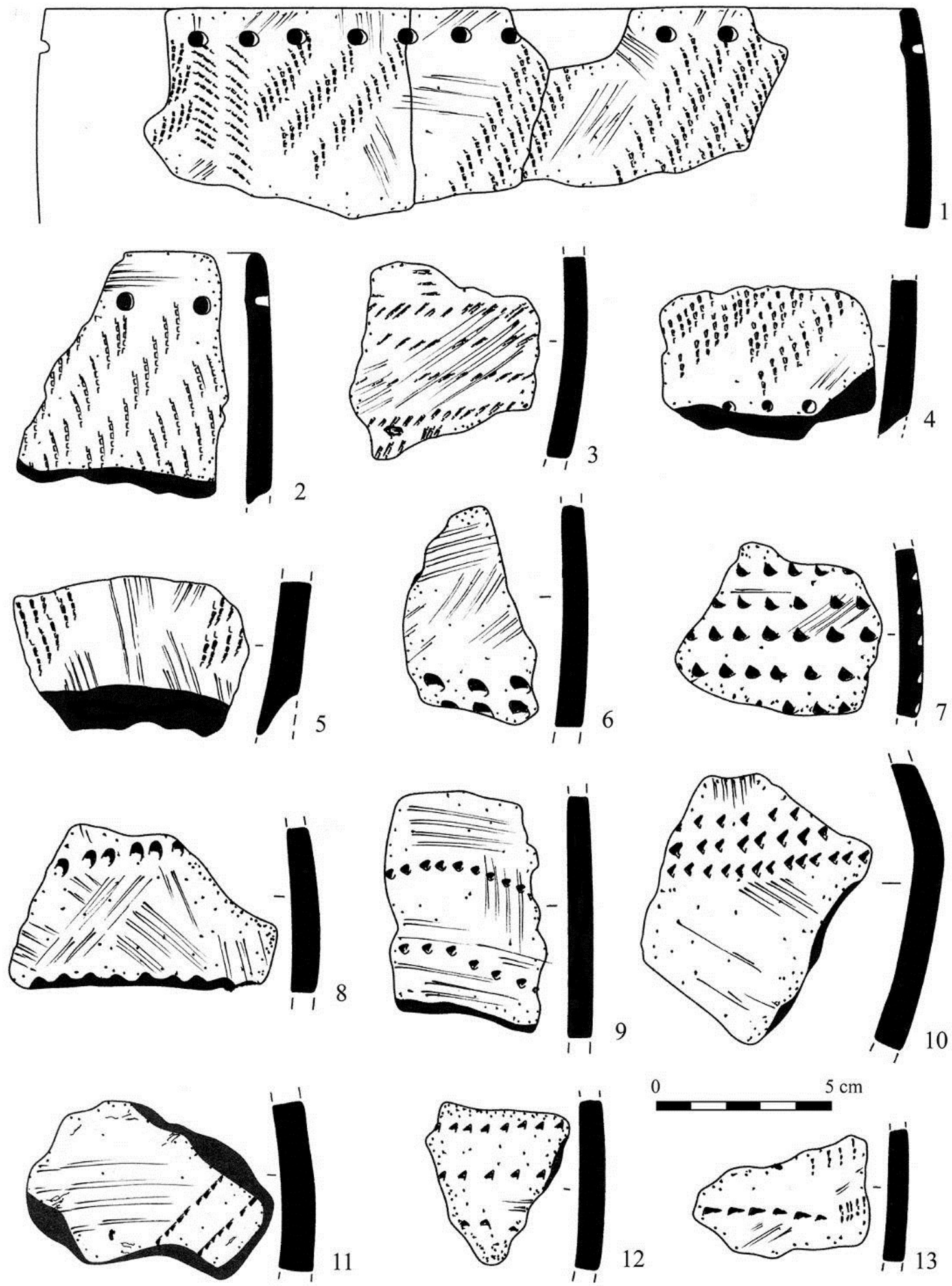

Рисунок 2 - Керамика второго этапа карамышевской культуры: 1-13- стоянка Университетская III

В первой четверти V тыс. до н.э. в Подонье начинают проникать традиции керамического производства северных культур с ямочно-гребенчатой орнаментацией (сначала раннельяловские, а затем и развитого этапа льяловской культуры), в среде которых на Верхнем Дону во второй четверти V тыс. до н.э. формируется долговская культура. Влияние среднедонской культуры проявилось в сохранении технологии производства сосудов при изменении форм и орнамента, появился тип ямочно-накольчатой керамики.

Тогда же в лесостепном Подонье фиксируются первые памятники среднестоговской культуры.
Среднедонская посуда, как и долговская, получает новые приемы оформления венчиков - выделенные, часто высокие, резко отогнутые наружу.

Смешение среднедонских, долговских и среднестоговских элементов в производстве и орнаментации посуды позволяет выделять поздний этап в развитии среднедонской культуры. Это сказывается в первую очередь в орнаментации керамики и формах сосудов - появляются памятники, где помимо накольчатой и накольчато-гребенчатой керамики есть посуда с гребенчатой и ямочно-гребенчатой орнаментацией (рис. 4). Датируется он второй половиной V тыс. до н.э. 

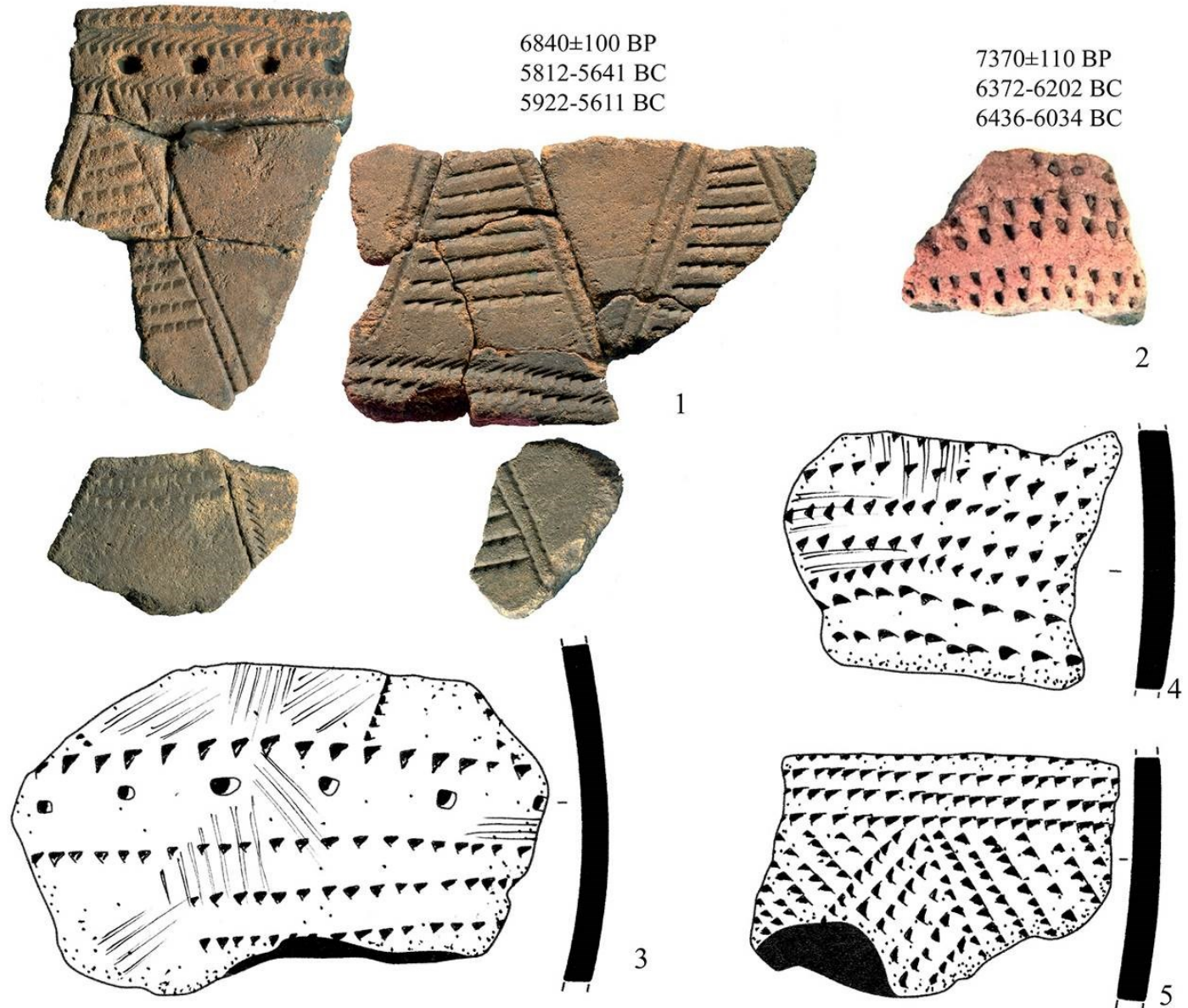

$7370 \pm 110 \mathrm{BP}$

$6372-6202 \mathrm{BC}$ 6436-6034 BC
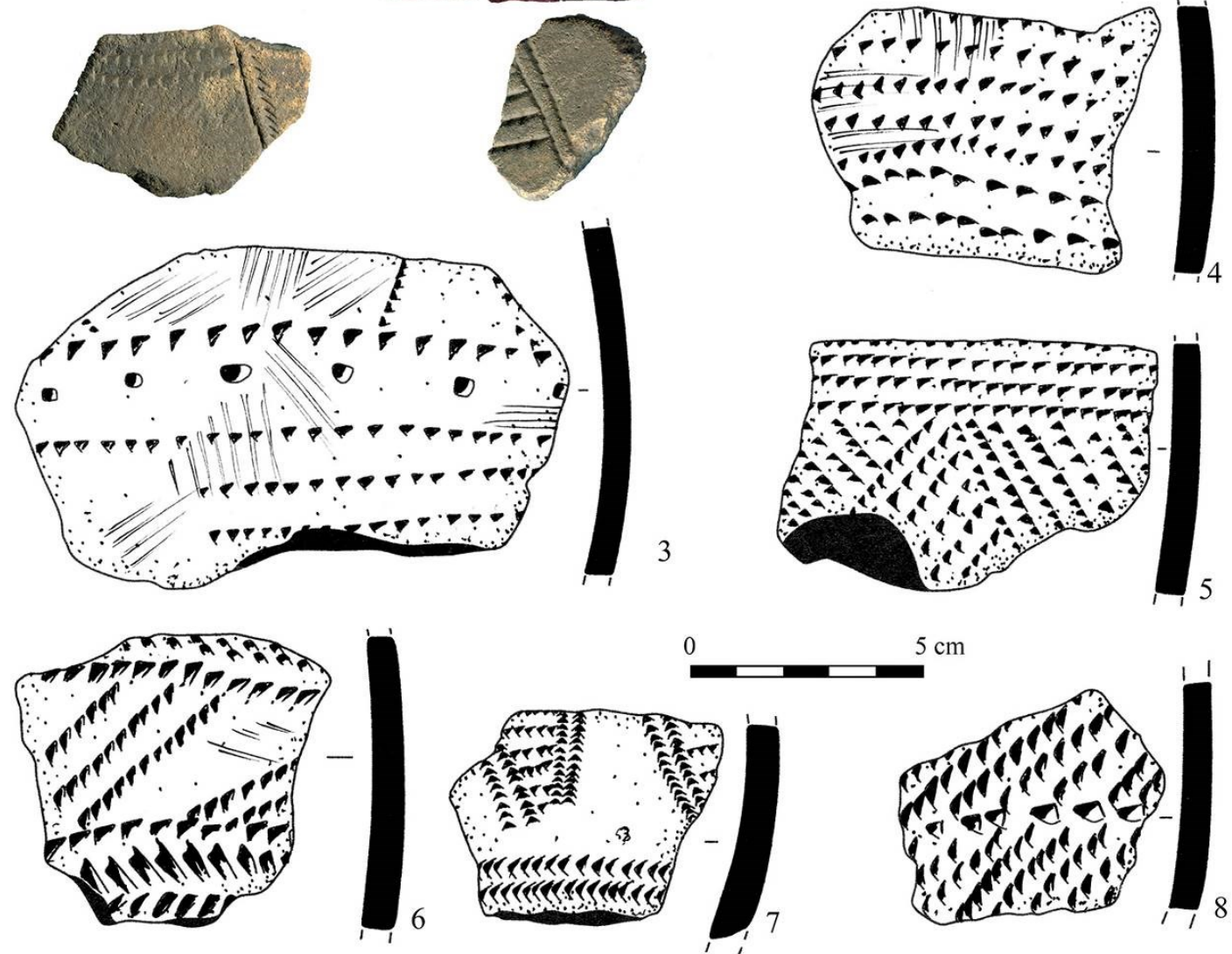

Рисунок 3 - Керамика среднедонской культуры: 1- Монастырская I, 2- Щучье II, 3-8-Университетская III

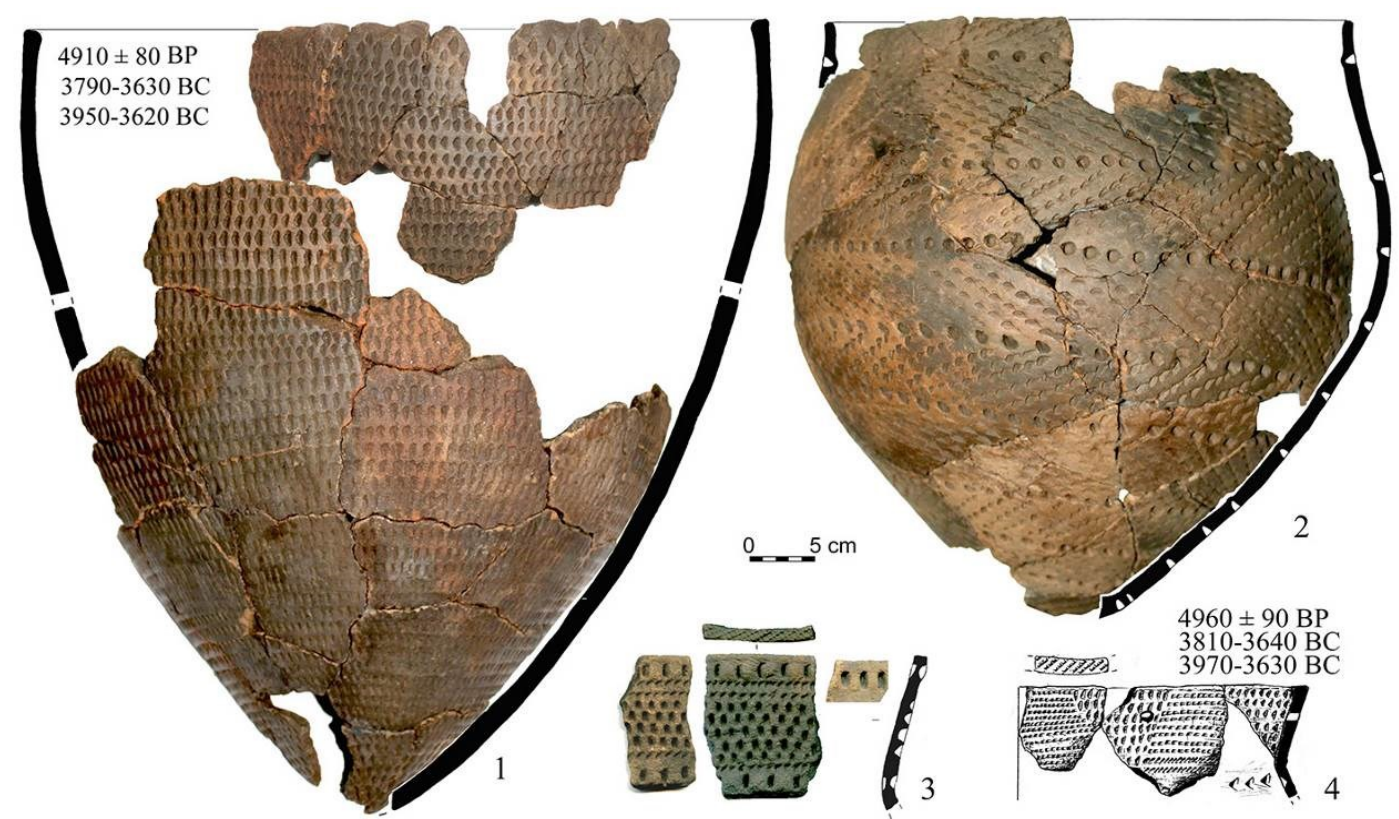

Рисунок 4 - Керамика позднего этапа среднедонской культуры: 1-4-стоянка Ямное 
Охарактеризовать каменный инвентарь, присущий именно поздней среднедонской культуре, затруднительно, поскольку исследованные памятники многослойные. Можно только отметить угасание пластинчатой техники и вкладышевых орудий, распространение двустороннеретушированных изделий, характерных для северных культур с ямочно-гребенчатой орнаментацией керамики.

В начале IV тысячелетия до н.э. среднедонская культура практически полностью исчезает и только некоторые проявления в виде использования накольчатой техники декорирования посуды фиксируется на рыбноозерском типе керамики. Этот период знаменует финальную, пережиточную фазу местного неолита, на смену которому приходит репинская культура.

\section{Buводы}

Основные теоретические положения, высказанные А.Т. Синюком относительно среднедонской культуры, остаются неизменными, корректировка хронологии и периодизации осуществляется только в рамках общих тенденций современного неолитоведения. Получение большого количества радиоуглеродных дат позволяет несколько иначе взглянуть на содержание этапов.

Периодизация среднедонской культуры, основываясь на современных представлениях о хронологии культурно-исторических процессов в Донской лесостепи в IV-IV тыс. до н.э., выглядит следующим образом.

Ранний этап - первая половина VI - третья четверть VI тыс. до н.э. Появление в лесостепном Подонье первых памятников с накольчатой керамикой и пластинчатым каменным инвентарем, затем их распространение на широкой территории, взаимодействие населения с карамышевским.

Развитой этап - последняя четверть VI - первая четверть V тыс. до н.э. Распространение накольчатогребенчатой посуды, орнамент полностью заполняет внешнюю поверхность сосудов.

Поздний этап - вторая четверть $\mathrm{V}$ - конец V тыс. до н.э. Сильное влияние энеолитических культур и культур с ямочно-гребенчатой орнаментацией керамики. Формирование синкретических типов - черкасского, накольчато-ямочного.

Пережиточный этап - начало IV тыс. до н.э. Финал среднедонских традиций, слабовыраженный в рыбноозерском типе керамики.

Главной спецификой донского региона в позднем неолите становится удивительная способность местного (среднедонского) населения приспосабливаться к внешним культурным воздействиям, трансформировать собственные керамические традиции, при этом оставаясь верными традиционному наколу.

\section{Список литературы:}

1. Синюк А.Т. Население бассейна Дона в эпоху неолита. Воронеж: Издательство Воронежского университета, 1986. $181 \mathrm{c}$.

2. Синюк А.Т. Памятники неолита и энеолита на Среднем Дону: автореф. дис. ... канд. ист. наук. М., 1971. 22 c.

3. Валукинский Н.В. Материалы к археологической карте территории г. Воронежа // Советская археология. 1948. Т. Х. С. 291-301.
4. Пряхин А.Д., Синюк А.Т. Древности из зоны Воронежского моря. Воронеж: Центрально-Черноземное книжное издательство, 1968. 32 с.

5. Синюк А.Т. Неолитический материал нижневоронежской многослойной стоянки Университетской-3 // Известия Воронежского государственного педагогического института. Т. 198. Археологические памятники на территории СССР и их изучение в высшей педагогической школе (по материалам восточно-европейской лесостепи). Воронеж: ВГПИ, 1978. С. 26-62.

6. Синюк А.Т. История населения донской лесостепи в V-II тысячелетиях до н.э.: автореф. дис. ... дра ист. наук. М., 1985.35 с.

7. Гапочка С.Н. Неолитические материалы стоянки Щучье II в Среднем Побитюжье // Археологические памятники бассейна Дона. Воронеж: Воронежский госпедуниверситет, 2004. С. 48-59.

8. Гапочка С.Н., Крючков М.А. Некоторые итоги исследования стоянки Затон I на юге лесостепного Подонья // Археологические памятники бассейна Дона. Воронеж: Воронежский госпедуниверситет, 2004. C. $72-82$.

9. Сурков А.В. Неолитические памятники Среднего Похоперья. Воронеж: ВГПУ, 2007. 122 с.

10. Сурков А.В. К вопросу о культурном статусе неолитических памятников с накольчато-гребенчатой керамикой на Верхнем Дону // Археология восточноевропейской лесостепи. Вып. 2. Т. 1. Пенза: Копи-Ризо, 2008. С. 105-112.

11. Сурков А.В. Стоянка Ивница на р. Воронеж: Итоги исследования 2010-2012 гг. // Археологические памятники Восточной Европы. Вып. 15. Воронеж: Издательско-полиграфический центр «Научная книга», 2013. С. 167-186.

12. Сурков А.В. Стоянка Ступино - новый ранненеолитический памятник на Верхнем Дону // Тверской археологический сборник. Вып. 10. Тверь: ООО «Издательство «Триада», 2015. С. 168-173.

13. Смольянинов Р.В. Ранний неолит Верхнего Дона (по данным керамических комплексов): автореф. дис. ... канд. ист. наук. СПб., 2009. 30 с.

14. Скоробогатов А.М., Смольянинов Р.В., Сурков А.В., Ойнонен М., Посснерт Г. Хронология неолитических памятников лесостепного Подонья // Радиоуглеродная хронология эпохи неолита Восточной Европы VII-III тысячелетия до н.э. / сост. Г.И. Зайцева, О.В. Лозовская, А.А. Выборнов, А.Н. Мазуркевич. Смоленск: Свиток, 2016. С. 244-260.

15. Выборнов А.А., Кулькова М.А., Ойнонен М., Посснерт Г. Новые радиоуглеродные даты неолитических памятников Подонья // Известия Самарского научного центра РАН. 2017. Т. 19, № 3 (2). С. 366-369.

16. Выборнов А.А., Сурков А.В. Новые данные по хронологии среднедонского неолита // Археологические памятники Восточной Европы. Вып. 13. Воронеж: ВГПУ, 2009. С. 58-59.

17. Сурков А.В., Скоробогатов А.М. Многослойная стоянка Ямное: материалы исследований. Воронеж: ВГПУ, 2012. $82 \mathrm{c.}$

18. Сурков А.В. Проблемы изучения происхождения раннего неолита лесостепного Дона // XXI Уральское археологическое совещание, посв. 85летию со дня рожд. Г.И. Матвеевой и 70-летию со дня рожд. И.Б. Васильева. Самара: Изд-во СГСПУ; ООО «Порто-принт», 2018. С. 73-75. 
19. Гапочка С.Н., Крючков М.А., Сурков А.В. Периодизация неолита, энеолита лесостепного Дона в трудах А.Т. Синюка // Проблемы археологии Восточной Европы в работах профессора А.Т. Синюка (к изданию «Избранных трудов»). Воронеж: Воронежский государственный педагогический университет, 2016. C. 52-55.

20. Смольянинов Р.В., Куличков А.А., Юркина Е.С. Стоянка среднедонской культуры Доброе 9 на Верхнем Дону // XXI Уральское археологическое совещание, посв. 85-летию со дня рожд. Г.И. Матвеевой и 70-летию со дня рожд. И.Б. Васильева. Самара: Издво СГСПУ; ООО «Порто-принт», 2018. С. 67-71.
21. Синюк А.Т. Стоянка Монастырская-І как источник для выделения мезолита и периодизации неолита на Среднем Дону // Избранные труды. Воронеж: Воронежский государственный педагогический университет, 2015. С. 261-272.

22. Скоробогатов А.М. Энеолитические памятник Донской лесостепи: автореф. дис. ... канд. ист. наук. Воронеж, 2011.23 c.

23. Васильева И.Н. К вопросу о гончарных традициях неолитического населения Подонья // Известия Самарского научного центра Российской академии наук. 2017. Т. 19, № 3 (2). С. 370-379.

Исследование выполнено за сиет гранта Российского научного фонда (проект № 17-78-20048).

\section{MIDDLE-DON NEOLITHIC CULTURE: PROBLEMS OF SELECTION, CHRONOLOGY AND PERIODIZATION}

(C) 2019

Surkov Aleksey Vladimirovich, candidate of historical sciences, archaeologist

Center for Security Archaeological Research (Voronezh, Russian Federation)

Abstract. The paper deals with the main results of the Middle-Don Neolithic culture study. The contribution of A.T. Sinyuk is noted. The paper also contains some evolution of his views on the content of the early stage of the culture. So, the first periodization, done in 1971 as a result of Universitetskaya III site study, was then adjusted, especially after the excavations of Monastyrskaya I site. The culture chronology according to modern concepts fits into the IV-V millennium BC. The origin of the Middle-Don culture is debatable. New absolute dating allows us to consider the early stage in the first half of the VI - third quarter of the VI millennium BC and associate it with the first monuments with stroke ceramics and plate stone inventory. The author notes that there was an interaction of the Middle Don population with the Karamyshevsky population at the early stage. During the last quarter of the VI first quarter of $\mathrm{V}$ millennium $\mathrm{BC}$ stroke-ornamented-comb ware spread, ornament completely filled the outer surface of the vessels. Late stage - second quarter $\mathrm{V}-$ end $\mathrm{V}$ millennium BC, the syncretic types were formed. Vestigial stage - the beginning of IV millennium BC, there was an end of Middle-Don traditions, they were rare in the Rybnoozersky type of ceramics.

Keywords: Neolithic; archaeological culture; periodisation; chronology; forest-steppe Don; Voronezh river; Pobituzhie; Universitetskaya III site; Monastyrskaya I site; Dobroe 9 site; Vasilievsky cordon 7 site; ceramics; ornamentation; stroke; Karamyshevskaya culture; Middle-Don culture.

УДК 903.4

DOI 10.24411/2309-4370-2019-12222

Статья поступила в редакцию 16.02.2019

\section{ПЕРЕСМОТР МАТЕРИАЛОВ ПОСЕЛЕНИЯ КАМЕННОГО ВЕКА РИЙГИКЮЛА І (ЭСТОНИЯ)}

(C) 2019

Хрусталева Ирина Юрьевна, докторант кафедры лабораторной археологии;

младший научный сотрудник отдела археологии Восточной Европы и Сибири

Тартуский университет (2. Тарту, Эстонская Республика); Государственный Эрмитаж

(2. Санкт-Петербург, Российская Федерация)

Крийска Айвар, доктор, профессор кафедры лабораторной археологии

Тартуский университет (2. Тарту, Эстонская Республика)

Холкина Маргарита Алексеевна, кандидат исторических наук,

старший преподаватель кафедры археологии; инженер отдела региональной геоэкологии и морской геологии

Санкт-Петербургский государственный университет (2. Санкт-Петербург, Российская Федерация);

Всероссийский научно-исследовательский геологический институт им. А.П. Карпинского

(2. Санкт-Петербург, Российская Федераиия)

Аннотация. Памятник Рийгикюла I на северо-западе Эстонии, открытый и исследованный в начале 1950х гг., является важным источником информации о быте и хозяйстве населения каменного века Прибалтики и одним из немногих поселений в Эстонии с остатками жилищ. Помимо двух углубленных построек здесь было найдено несколько очагов, два целых человеческих скелета и отдельные человеческие кости, а также богатый инвентарь, представленный обломками глиняных сосудов, изделиями и отходами производства из кварца, кости, рога, кремня и пр. Первоначально памятник был интерпретирован как одно долговременное поселение. Однако появлявшиеся новые данные по другим памятникам региона, а также частичный повторный анализ глиняной посуды и полученные AMS датировки по человеческим костям показали необходимость пересмотра всех материалов. Предварительные результаты этих работ представлены в нашей статье. Было установлено, что на поселении существовало как минимум четыре постройки, соотносимые с материалами культур нарвской и гребенчатой керамики, что указывает на то, что, по крайней мере, частично они бы- 